\title{
Does allicin combined with vitamin B-complex have superior potentials than alpha-tocopherol alone in ameliorating lead acetate-induced Purkinje cell alterations in rats? An immunohistochemical and ultrastructural study
}

\author{
H.N. Mustafa, A.M. Hussein \\ Anatomy Department, Faculty of Medicine, King Abdulaziz University, Jeddah, Saudi Arabia
}

[Received: 17 April 2015; Accepted: 2 June 2015]

Background: The current article aims to explore the protective potentials of $\alpha$-tocopherol alone and the combination of allicin and vitamin B-complex against lead-acetate neurotoxicity on the cerebellar cortex.

Materials and methods: Forty rats were divided into four groups $(n=10)$. Group 1 was the control group; Group 2 received $10 \mathrm{mg} / \mathrm{kg}$ body weight (BW) of lead acetate; Group 3 was exposed to $10 \mathrm{mg} / \mathrm{kg} B W$ of lead acetate plus a combination of allicin (100 mg/kg BW) and vitamin B-complex (40 mg/kg BW); Group 4 was administered lead acetate $(10 \mathrm{mg} / \mathrm{kg} \mathrm{BW})$ and $\alpha$-tocopherol $(100 \mathrm{mg} / \mathrm{kg} \mathrm{BW}$ ). The animals received the treatment for 60 days by oral gavage. All the groups were studied ultrastructurally and immunohistochemically with glial fibrillary acidic protein (GFAP).

Results: The affected groups revealed shrunken and degenerated Purkinje cells with irregular nuclei. The cytoplasm comprised several lysosomes, unhealthy mitochondria, and dilated Golgi saccules. The myelinated nerve fibres demonstrated breaking of the myelin sheaths, apparent vacuoles, and broad axonal spaces. Immunohistochemically, there was a tremendous surge in GFAP-positive astrocytes in the lead acetate-treated group. These histological and ultrastructural variations were ameliorated by the administration of $\alpha$-tocopherol and the combination of allicin and vitamin $B$ complex. Moreover, an apparent decrease in the number of GFAP-positive astrocytes was obvious in the protected groups.

Conclusions: Although both $\alpha$-tocopherol and the combination of allicin and vitamin $B$-complex can be used as possible adjuvant therapies to ameliorate nervous system ailments attributable to lead acetate, $\alpha$-tocopherol showed more protective potential. (Folia Morphol 2016; 75, 1: 76-86)

Key words: allicin, Purkinje cells, astrocytes, glial fibrillary acidic protein, oligodendrocyte, myelin figure

\section{INTRODUCTION}

The cerebellum is the crucial subcortical structure for learning and controlling the movement [7]. It is responsible for the timing, coordination, and fine- -tuning of movement. Accordingly, injuries to the cerebellum may cause postural instability, loss of balance, and abnormal gait [46]. Lead $(\mathrm{Pb})$ is one of the most hazardous environmental contaminants known 
to humans [40]. The main sources of human exposure are through food consumption, air inhalation, and drinking of contaminated water [12].

Exposure to heavy metals like lead may cause cerebellar dysfunction [31, 54]. Sustained exposure to this metal can cause permanent abnormalities, especially in Purkinje cells $[19,25]$. Astrocytes play an essential role in the different functions of the central nervous system (CNS) [10,44]. Any injury to the brain, either metabolic or physical, may directly affect the glial cells [8]. One critical event during astrocyte differentiation is the change in the expression of the glial marker called glial fibrillary acidic protein (GFAP) $[9,17]$.

Lead is known to cause the production of reactive oxygen species (ROS), which induce lipid peroxidation, diminish saturated fatty acids (FAs), and create an upsurge of unsaturated FA components in cell membranes $[2,30]$. The body also produces endogenous ROS, which are formed when fat undergoes oxidation, so antioxidants are beneficial as protective entities against ROS $[22,47]$. The imbalance between the production of free radicals and the ability of the body to detoxify their harmful effects can produce oxidative stress. The exposure of cells to adverse environmental disorders can prompt the over-production of ROS, such as the superoxide anion $\left(\mathrm{O}_{2}-\right)$, hydrogen peroxide $\left(\mathrm{H}_{2} \mathrm{O}_{2}\right)$, superoxide dismutase (SOD), hydroxyl radical $(\mathrm{OH})$, and organic hydroperoxide (ROOH) in tissues [34, 38].

Allium sativum (garlic) has been used since ancient times as a flavouring agent for foodstuffs and as a medicinal substance $[29,42]$. Allium sativum has hypolipidemic, hypoglycaemic, antihypertensive, hepatoprotective, antioxidant, and immunomodulating pharmacological effects; it is also an antidote for heavy metal poisoning $[16,29]$. Many of the advantageous health-associated properties of Allium sativum have been attributed to its organosulfur substances, especially allicin (thio-2-propene-1-sulfinic acid S-allyl ester). Allicin is the main effective element that is produced during the crushing of Allium sativum by means of the reaction of alliin, a non-protein amino acid, along with the pyridoxal phosphate-containing enzyme, alliinase $[4,16]$.

The goal of the current study is to determine whether allicin combined with vitamin B-complex has a superior role than $\alpha$-tocopherol alone in protecting the Purkinje cells against toxic alterations caused by lead acetate.

\section{MATERIALS AND METHODS}

\section{Ethical approval}

This study was conducted after approval by the Medical Research Ethics Committee of the Faculty of Medicine, King Abdulaziz University.

\section{Animals}

Forty male adult Wistar rats weighing $200 \pm 20 \mathrm{~g}$ were obtained from the university's Animal House and were distributed randomly into four groups of animals $(n=10)$. The rats were individually housed in stainless steel cages at controlled temperature $\left(22 \pm 2^{\circ} \mathrm{C}\right)$ and humidity (55 $\pm 10 \%)$ for a $12 / 12$ h cycle of light/ /dark with access to food and drinking water ad libitum. The experimental procedures were carried out in accordance with the international guidelines for the care and use of animals in the laboratory.

\section{Chemicals}

Lead acetate trihydrate $\left[\left(\mathrm{C}_{2} \mathrm{H}_{3} \mathrm{O}_{2}\right)_{2} \mathrm{~Pb} .3 \mathrm{H}_{2} \mathrm{O}\right](\mathrm{PbAc})$ was purchased from Sigma-Aldrich Chemicals Co. (St. Louis, Missouri, USA). A $0.5 \%$ of $\mathrm{Pb}$ solution was prepared by dissolving $5 \mathrm{~g}$ of PbAc in $1000 \mathrm{~mL}$ of distilled acidified water; the solution was replaced daily to minimize the presence of lead precipitates. Vitamin B-complex and $\alpha$-tocopherol acetate were also obtained from Sigma-Aldrich Chemicals Co. A $5000 \mathrm{mg} / \mathrm{L}$ solution of novel stabilised AEAllicin was purchased from Allicin International Limited, United Kingdom. The purity and concentration of the latter solution was determined by high-performance liquid chromatography $[15,41]$.

\section{Experimental design}

Administration of the chemicals was done by oral gavage for a period of 60 days. Group 1, the control group, received $1 \mathrm{~mL}$ distilled water. Group 2 was given $10 \mathrm{mg} / \mathrm{kg}$ body weight (BW) of lead acetate $(\mathrm{PbAc})[1,48]$. Group 3 received a combination of allicin (100 mg/kg BW) and vitamin B-complex (40 mg/ $/ \mathrm{kg} \mathrm{BW}$ ) prior to $10 \mathrm{mg} / \mathrm{kg}$ BW of PbAc $[21,28]$. Group 4 received $100 \mathrm{mg}$ of $\alpha$-tocopherol acetate/kg BW prior to $10 \mathrm{mg} / \mathrm{kg}$ BW of PbAc $[28,53]$. In previous studies, $\alpha$-tocopherol acetate at a dose of $100 \mathrm{mg} / \mathrm{kg}$ BW was found to be effective in reducing toxicity [13].

\section{Cerebellum histology}

The animals were decapitated at the end of the experiment. The cerebellum was removed, weighed, and then fixed in $10 \%$ neutral buffered formalin. 
Paraffin sections $5 \mu \mathrm{m}$ in thickness were prepared. For each specimen, at least 3 to 5 slides were stained with haematoxylin and eosin (H\&E) using standard techniques for general histology examination, and examined with an Olympus BX53 microscope equipped with an Olympus DP73 camera (Olympus, Tokyo, Japan) at different magnifications to allow for the observation of the degenerative changes [32, 33].

\section{Morphometric study}

Ten slides of non-overlapping fields from each group, one slide from each animal, were analysed with the use of Image-Pro Plus v6 (Media Cybernetics Inc., Bethesda, Maryland, USA). The mean diameter of the thickness of the molecular, granular, and Purkinje cell layers in each group was measured. In addition, the number of Purkinje cells and granular cells was counted.

\section{Immunohistochemical study}

Serial paraffin sections of $5-\mu \mathrm{m}$ thickness were deparaffinised and dehydrated, including positive control sections from the cerebellum. The endogenous peroxidase activity was blocked with $0.05 \%$ hydrogen peroxide in absolute alcohol for $30 \mathrm{~min}$. The slides were washed for $5 \mathrm{~min}$ in phosphate-buffered saline (PBS) at a pH of 7.4. To unmask the antigenic sites, sections were placed in a $0.01 \mathrm{M}$ citrate buffer ( $\mathrm{pH} \mathrm{6)}$ in a microwave for $5 \mathrm{~min}$. The slides were incubated in $1 \%$ bovine serum albumin dissolved in PBS for $30 \mathrm{~min}$ at $37^{\circ} \mathrm{C}$ in order to prevent nonspecific background staining. Two drops of ready-to-use primary antibodies were applied to the sections (except for the negative control) and then incubated for $90 \mathrm{~min}$ at room temperature. GFAP [1:100] was applied to the sections. The slides were rinsed with PBS and then incubated for 60 min with anti-mouse immunoglobulins (secondary antibody) conjugated to a peroxidase-labelled dextran polymer (Dako, Denmark). In order to detect the reaction, the slides were incubated in 3,3'-diaminobenzidine for $15 \mathrm{~min}$. The slides were counterstained with Mayer's haematoxylin and then dehydrated, cleared, and mounted by di-N-butyle phthalate in xylene. GFAP-positive cells appeared brown, and the nuclei appeared blue $[26,45,51]$.

\section{Ultrastructure study}

Cerebellar samples of approximately $1 \mathrm{~mm}^{3}$ were obtained and immersed in $2.5 \%$ glutaraldehyde in $0.1 \mathrm{M}$ phosphate buffer at $4^{\circ} \mathrm{C}$ for $3 \mathrm{~h}$ and post-fixed in $1 \%$ osmium tetraoxide. After dehydration in ascen- ding grades of ethanol, the tissues were embedded in Epon 812. Semithin sections were prepared from the blocks, stained using toluidine blue, and observed with an Olympus microscope. Demonstrative areas of the semithin section were chosen. Next, 50-60 nm thick ultrathin sections were cut using an ultramicrotome (NOVA, LKB 2188, Bromma, Sweden); uranyl acetate and lead citrate were used to stain the tissues, which were then inspected with a Philips 201 transmission electron microscope at $60-80 \mathrm{kV}$ at the Transmission Electron Microscope Unit (Philips Industries, Eindhoven, Netherlands) [32].

\section{Statistical analysis}

Quantitative data were expressed as the mean and standard deviations of different parameters between the treated groups. Data were analysed using a one-way analysis of variance (ANOVA) followed by a least significant difference post hoc test. All statistical analyses were implemented using the Statistical Package for the Social Sciences (SPSS), version 22. The values were considered significant when $p<0.05$ [33].

\section{RESULTS}

\section{General assessment}

The control rats were normal, healthy and did not display any signs of neurologic irregularity. Four rats from the group that received the lead acetate showed many negative neurologic signals, such as a decrease in vitality, muscle-mass weakness, tremors, an abnormal gait, lack of stability and equilibrium. At the end of the experiment, the rats' hind limbs of the lead treated group were nearly paralysed and 1 rat died. Rats from the groups treated with lead acetate and protected by combined allicin and vitamin B-complex or $\alpha$-tocopherol; both animal groups demonstrated a decrease in activity near the end of the study.

\section{Light microscopic results}

The H\&E-stained paraffin sections of the control group demonstrated a normal histoarchitecture of the cerebellar cortex (Fig. 1A).

H\&E stained areas of lead acetate group demonstrated multifocal neuronal affection; the monolayer arrangement of the Purkinje cells was sparse and disrupted in many areas, and gone completely in several areas, where they had been replaced by empty spaces. The majority of the Purkinje cells were shrun- 


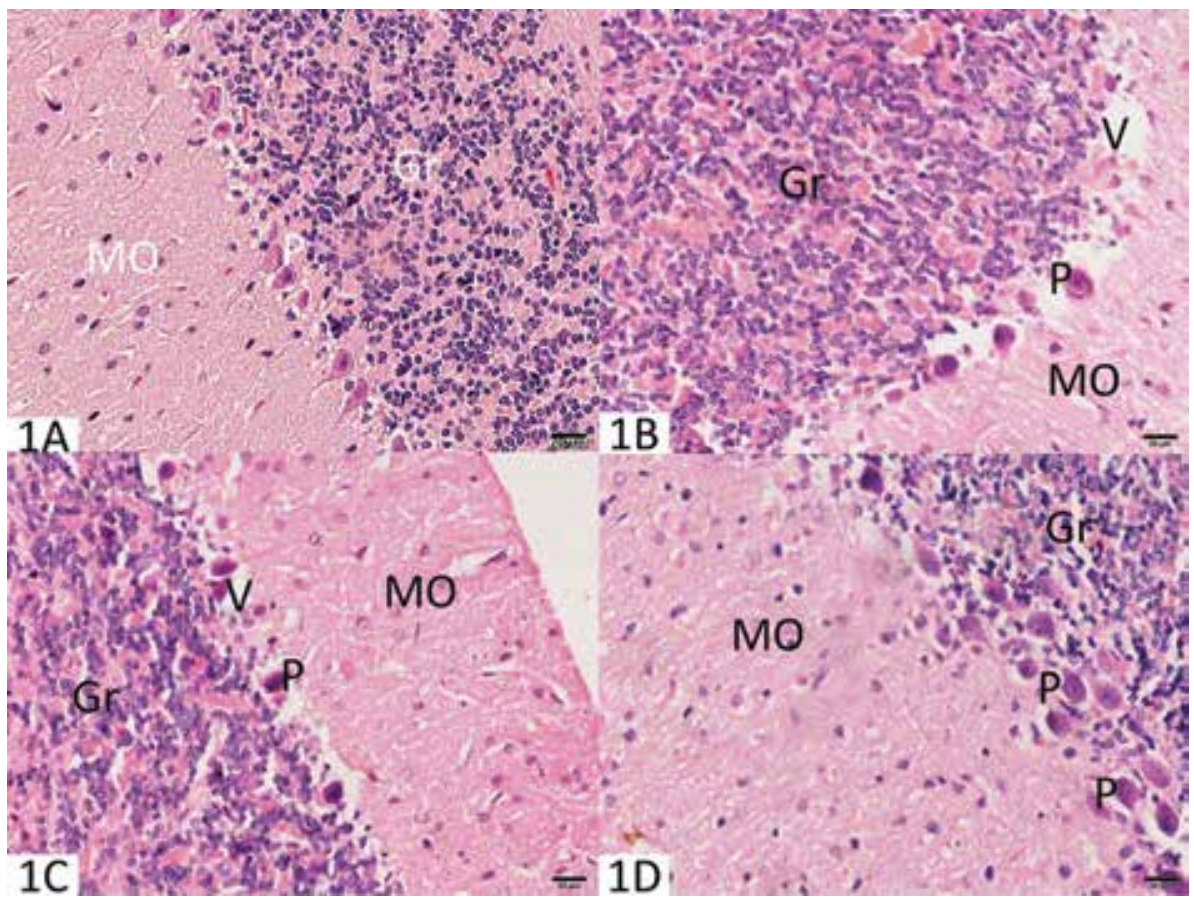

Figure 1. A. A photomicrograph of the cerebellar cortex of the control group demonstrated the outer molecular layer (Mo), the Purkinje cell layer $(\mathrm{P})$, and the inner granular layer $(\mathrm{Gr})$; B. Rats treated with lead acetate showed the disappearance of many Purkinje cells, which left empty spaces (V); C. The group treated with lead acetate and allicin and vitamin B showed the monolayer of Purkinje cells $(P)$ in between the molecular (Mo) and granular layers (Gr), with a vacuolated area around (V); D. The group treated with lead acetate and $\alpha$-tocopherol showed multilayers of Purkinje cells (P) in between the molecular (Mo) and granular layers (Gr). Scale bar: $20 \mu \mathrm{m}$.

ken, irregular, and abnormal in outline with deep, homogenous, vacuolated cytoplasm, an absence of Nissl's granules, and dark nuclei; ill-identified cytoplasmic processes were also noticed. Many neuroglia cells had accumulated around the Purkinje cells. The molecular layer seemed to be much thinner and had moderately vacuolated neuropil (perineural spaces) with accumulations of neuroglial cells around some of them. Few cells showed vesicular nuclei, while others revealed pyknotic nuclei or complete karyolysis. The cellular structure within the granular layer tended to be tiny and oval-shaped or rounded, and had pyknotic and deeply stained nuclei (Fig. 1B).

H\&E stained sections of the lead acetate and combined allicin and vitamin B-complex treated group revealed Purkinje cells arranged in a monolayer with moderate disorganisation. A number of Purkinje cells appeared damaged and encircled with vacuolated cytoplasm among the numerous obviously typical cells with central vesicular nuclei. The molecular and granular layers were approximately comparable to the control, there was a clear sparsity of Purkinje cells in the Purkinje layer, and the nuclei appeared irregular and dark (Fig. 1C).
H\&E stained sections of the lead acetate and $\alpha$-tocopherol treated group revealed a monolayer or multilayer arrangement of Purkinje cells, with a slight loss of the normal pyriform shape along with mild disorganisation. Many damaged Purkinje cells encircled with vacuolated cytoplasm and irregular dark nuclei. These cells were present among the partially recovered Purkinje cells with central open-faced vesicular nuclei and extended apical dendrites. The molecular and granular layers were approximately similar to the control. The sparsity of the Purkinje cells in the Purkinje layer was approximately similar to that of the control, and the nuclei had regained their healthy appearance (Fig. 1D).

\section{Semithin sections stained with toluidine blue}

Control group revealed a normal histological picture (Fig. 2A).

Lead acetate group showed distortion and shrinkage of the Purkinje cells and absent nucleoli observed, with vacant areas between and surrounding the cells. The encompassing Bergmann glial cells were deeply stained compared with those of the control group. 


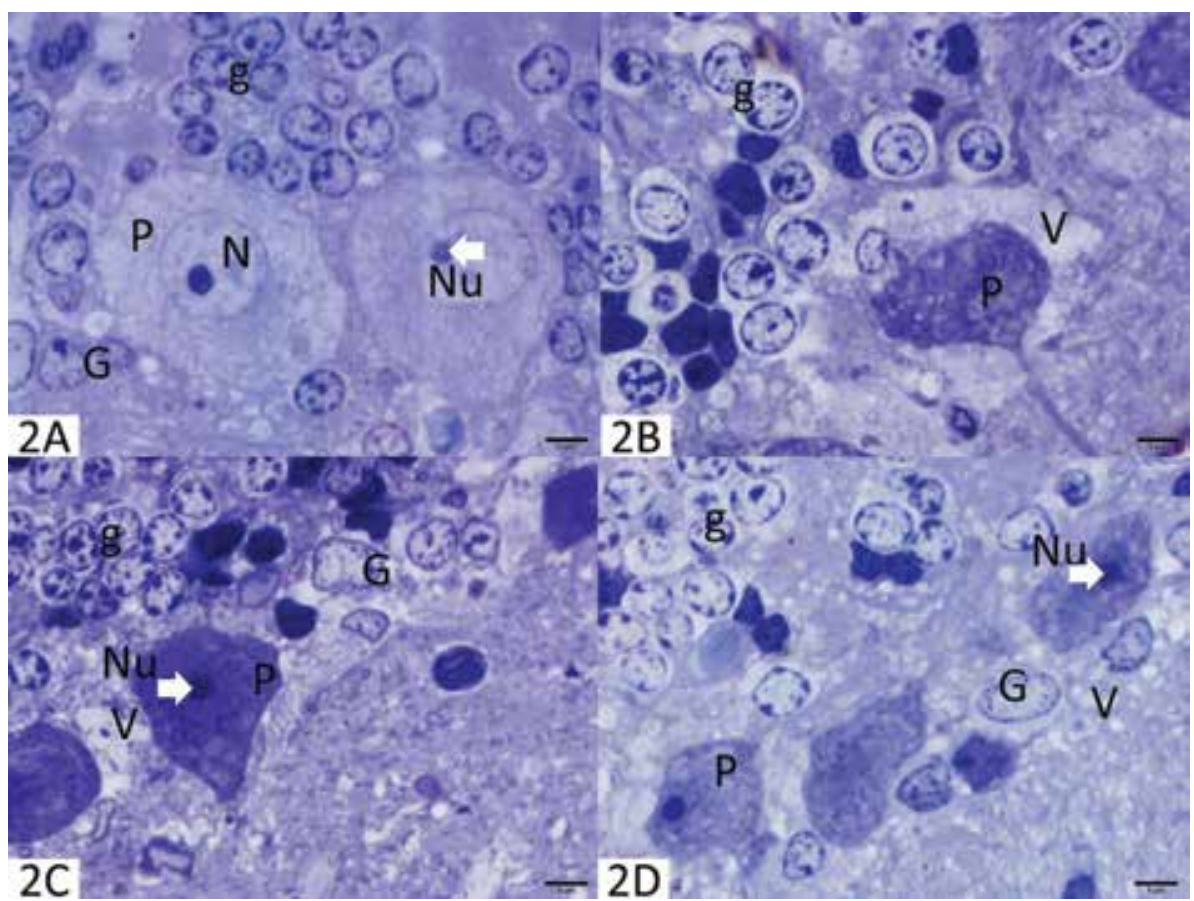

Figure 2. A. A photomicrograph of a semithin section of the cerebellar cortex of the control group displayed Purkinje cells $(P)$ with a nucleus (N) and a deeply stained nucleolus ( $\mathrm{Nu}$ ). Note the Bergmann glial cells (G) and the granular cells (g); B. The group treated with lead acetate presented Purkinje cells (P) with vacuoles (V). Note that the glial cells are deeply stained beside the Granule cells (g); C. The group treated with lead acetate and combined allicin and vitamin B exhibited Purkinje cells $(P)$ with a restored nucleolus. The glial cells $(G)$ are normal, and the granule cells $(\mathrm{g})$ seem normal; D. The group treated with lead acetate and $\alpha$-tocopherol exhibited Purkinje cells (P) with minimal vacuolated cytoplasm (V) and restoration of the nucleolus (Nu). The encompassing glial cells (G) tend to be approximately normal. The majority of the granule cells $(\mathrm{g})$ seem normal. Scale bar: $5 \mu \mathrm{m}$.

Numerous granule cells and many irregular, deeply stained cells appeared in the granule cell layer (Fig. 2B).

Lead acetate and combined allicin and vitamin B-complex treated group revealed the Purkinje cells appeared dark, with minimal vacuoles within their cytoplasm and restored nuclei and nucleoli. The vacant areas in the encompassing neuropils remained. The encircling glial cells had been essentially similar to the control group in terms of staining, and the majority of the granule cells looked normal. Many darker cells appeared in the granule cell layer (Fig. 2C).

Lead acetate and $\alpha$-tocopherol treated group showed the Purkinje cells appeared healthier, restored their architecture and appeared euchromatic in comparison with the control group, with minimal or no vacuolated cytoplasm and restoration of the nucleolus. The vacant areas in the encompassing neuropil remained. The encircling glial cells appeared like that of the control group in terms of their staining, and the majority of the granule cells were healthy and improving. A small number of darker cells appeared in the granule cell layer (Fig. 2D).

\section{Immunohistochemical staining for GFAP}

The study of the control group revealed the existence of GFAP-positive fibrous astrocytes with lengthy and thin processes. Smaller-sized oligodendrocytes had shorter, fewer processes and spindle-shaped microglia were observed. The granular layer demonstrated protoplasmic astrocytes with thicker processes (Fig. 3A).

Lead acetate group revealed the cerebellar cortex exhibited a more positive immunoreaction and seemed to be substantially larger within the 3 cortical layers, as well as apparent protoplasmic processes of many astrocytes (Fig. 3B).

Lead acetate and combined allicin and vitamin B-complex treated group showed little scattered positive immunostaining in the molecular and granular layers (Fig. 3C).

Lead acetate and $\alpha$-tocopherol treated group revealed scattered positive immunostaining in the molecular and granular layers with the processes of many astrocytes (Fig. 3D). 


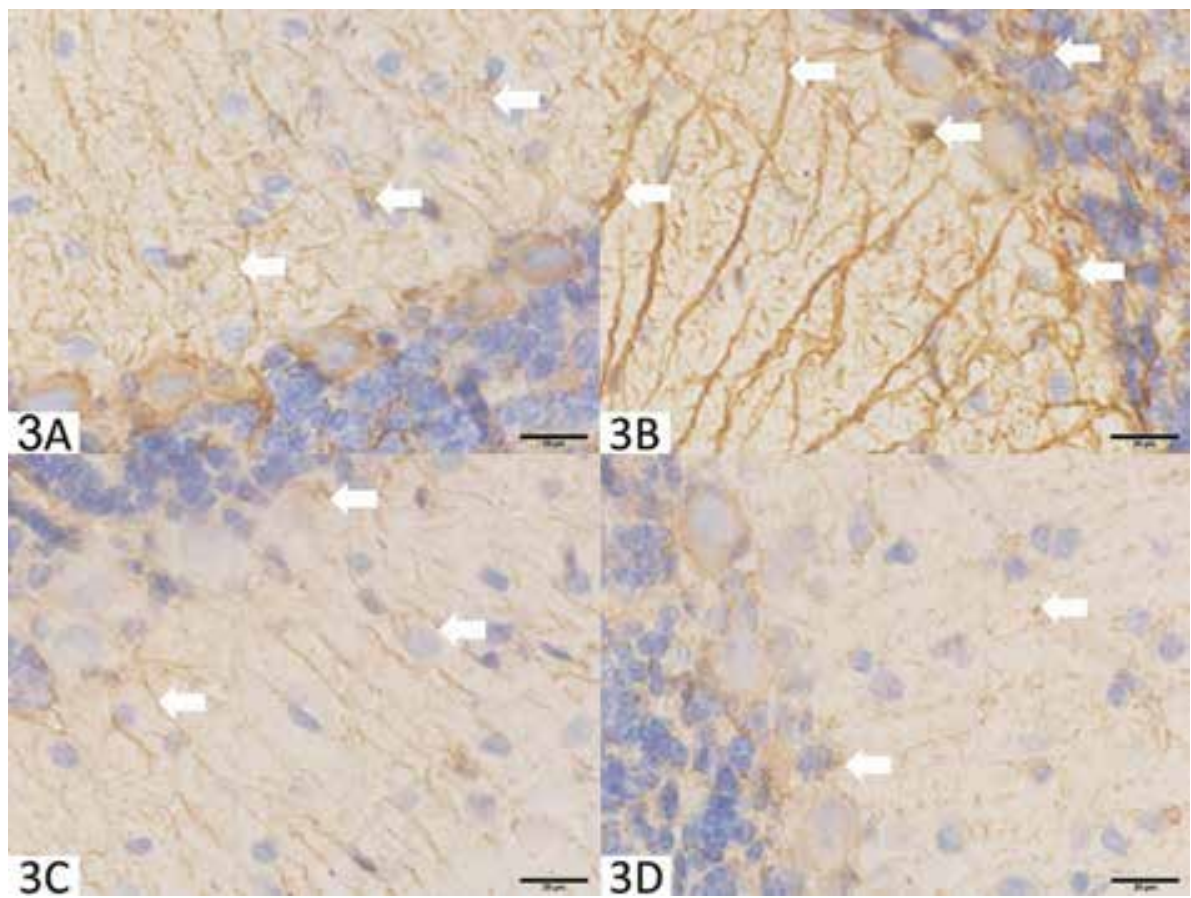

Figure 3. A. A photomicrograph of an immunohistochemical staining for glial fibrillary acidic protein in the cerebellar cortex of the control group displayed few scattered positive cells (arrows) in the molecular and granular layers; B. The group treated with lead acetate presented an increase in positive cells (arrows); C. The group treated with lead acetate and combined allicin and vitamin B exhibited little scattered positive immunostaining (arrows); D. The group treated with lead acetate and $\alpha$-tocopherol revealed several incidences of scattered positive immunostaining (arrows). Scale bar: $20 \mu \mathrm{m}$.

\section{Transmission electron microscopic study}

Study of the control cerebellar cortex exhibited a well-known normal ultrastructural picture (Figs. 4A, 5A, 5C).

Lead acetate group showed abnormally shrunken Purkinje cells with an electron-dense cytoplasm and ill-defined nuclei with prominent nucleoli were present. Dilated Golgi bodies, many unhealthy, ballooned mitochondria with damaged cristae and vacuolated vacant neuropils were observed. The myelin sheath of many axons was interrupted. In addition, the oligodendrocytes showed increased condensation of the nuclear chromatin (Figs. 4B, 5B, 5D).

Lead acetate and combined allicin and vitamin B-complex treated group revealed the Purkinje cells appeared relatively normal with an indented nucleus but no apparent nucleolus and a healthy mitochondria (Fig. 4C).

Lead acetate and $\alpha$-tocopherol treated group showed the Purkinje cells' nuclei appeared euchromatic with apparent nucleoli and surrounded by a healthy mitochondria (Fig. 4D).

\section{Quantitative morphometric study and statistical results}

There was a significant decline in the mean thickness of the cerebellar cortex layers (molecular, granular and Purkinje) in the lead acetate treated group in comparison with the control group. In lead acetate with combined allicin and vitamin B, the molecular, granular and Purkinje layers thickness were significantly lower than controls but was significantly higher than lead acetate group. In lead acetate with $\alpha$-tocopherol, the molecular, granular and Purkinje layers thickness were insignificantly different from controls but were significantly higher than lead acetate group (Table 1).

There was a significant decline in the mean numbers of the cerebellar cells (Purkinje and granular) in the lead acetate treated group in comparison with the control group. In lead acetate with combined allicin and vitamin B, the Purkinje and granular cells number was significantly lower than controls but the granular layer cells number was significantly higher than lead acetate group. In lead acetate with $\alpha$-tocopherol, the 


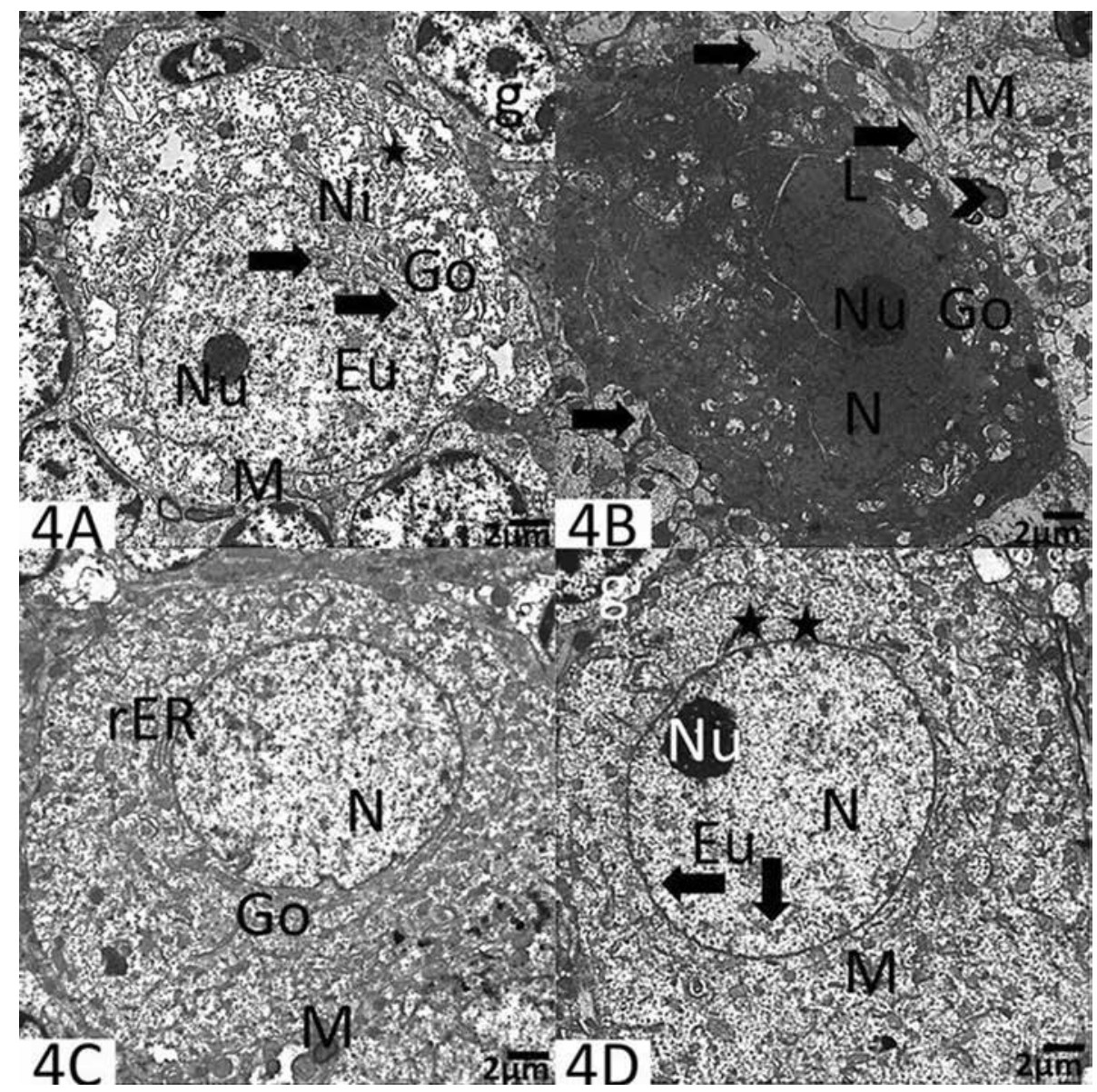

Figure 4. A. An electron micrograph of the control rats' cerebellar cortex showed part of the control Purkinje cell having an indented nucleus (black arrow) with an apparent rounded nucleolus $(\mathrm{Nu})$ and an abundant nuclear sap $(\mathrm{Eu})$. The cytoplasm shows short profiles of rough endoplasmic reticulum cisternae (star), numerous mitochondria (M), a well-developed perinuclear Golgi apparatus (Go), and Nissl's granules (Ni). Note the granule cell $(\mathrm{g})$ in the upper-right corner; B. The group treated with lead acetate demonstrated abnormal shrunken Purkinje cells with an electron-dense cytoplasm and an ill-defined nucleus (N) with a prominent nucleolus (Nu). Dilated Golgi bodies (Go), many mitochondria with damaged cristae $(\mathrm{M})$, and lysosomes $(\mathrm{L})$ are present. Note that the cells are encompassed by vacuolated vacant neuropils (arrows), and the myelin sheath of many axons is interrupted (arrowhead). Scale bar: $2 \mu \mathrm{m} ; \mathbf{C}$. The group treated with lead acetate and combined allicin and vitamin B showed part of the Purkinje cell that appears relatively normal with an indented nucleus (N) but no apparent nucleolus; it is surrounded by Golgi apparatus (Go), mitochondria (M), and rough endoplasmic reticulum (rER); D. The group treated with lead acetate and $\alpha$-tocopherol demonstrated part of the Purkinje cell nucleus (N) that appears euchromatic (Eu) with an apparent nucleolus (Nu) and surrounded by mitochondria (M) and rough endoplasmic reticulum cisternae (star). Scale bar: $2 \mu \mathrm{m}$.

Table 1. Comparison of the mean values of cerebellar layers' thickness $[\mu \mathrm{m}]$ of the experimental groups with the control group

\begin{tabular}{|c|c|c|c|c|}
\hline Layers & Control & Lead acetate & $\begin{array}{l}\text { Lead acetate with combined } \\
\text { allicin and vitamin B }\end{array}$ & $\begin{array}{l}\text { Lead acetate with } \\
\alpha \text {-tocopherol }\end{array}$ \\
\hline \multirow[t]{2}{*}{ Molecular layer } & $200.16 \pm 23.00$ & $155.18 \pm 9.86$ & $180.27 \pm 15.39$ & $211.61 \pm 8.55$ \\
\hline & & $\mathrm{p}<0.0001^{1}$ & $p=0.003^{1} ; p<0.0001^{2}$ & $p=0.073^{1} ; p<0.0001^{2}$ \\
\hline \multirow[t]{2}{*}{ Granular layer } & $205.74 \pm 25.39$ & $115.35 \pm 21.27$ & $173.76 \pm 13.53$ & $193.49 \pm 10.76$ \\
\hline & & $\mathrm{p}<0.0001^{1}$ & $\mathrm{p}<0.0001^{1} ; \mathrm{p}<0.0001^{2}$ & $p=0.115^{1} ; p<0.0001^{2}$ \\
\hline \multirow[t]{2}{*}{ Purkinje layer } & $19.11 \pm 5.17$ & $11.53 \pm 2.75$ & $15.57 \pm 2.02$ & $17.80 \pm 1.93$ \\
\hline & & $\mathrm{p}<0.0001^{1}$ & $p=0.011^{1} ; p=0.004^{2}$ & $p=0.328^{1} ; p<0.0001^{2}$ \\
\hline
\end{tabular}

Values are expressed as mean \pm standard deviation. The analysis was made using a one-way analysis of variance (ANOVA) test (least significant difference); ${ }^{1} \mathrm{p}$ : significance vs. control; ${ }^{2} \mathrm{p}$ : significance vs. lead group 


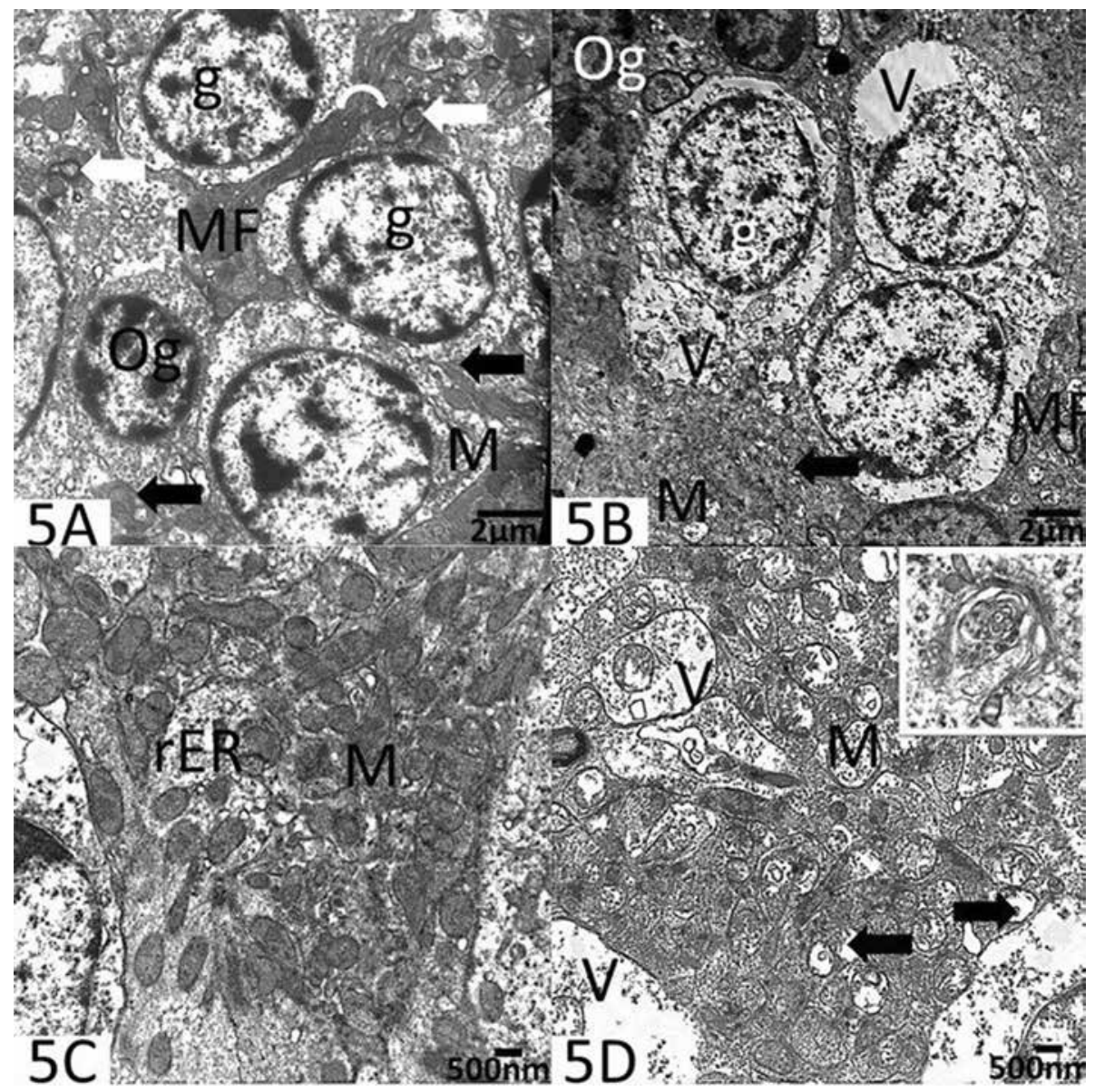

Figure 5. A. The control rats displayed oligodendrocyte $(0 \mathrm{~g})$ with darker and smaller nuclei and granule cells $(\mathrm{g})$ with larger and lighter nuclei. Profiles of rough endoplasmic reticulum cisternae (black arrow) can be seen. Myelinated fibres (white arrows) with spherical mitochondria (curved arrows) and mossy fibres (MF) are visible; B. The group treated with lead acetate demonstrated an oligodendrocyte $(0 \mathrm{~g})$ with increased condensation of nuclear chromatin and granule cells $(\mathrm{g})$ surrounded by vacuolated vacant neuropils $(\mathrm{V})$ and unhealthy, ballooned, empty mitochondria (M). Scattered mossy fibres (MF) and rough endoplasmic reticulum (black arrow) can be seen. Scale bar: $2 \mu \mathrm{m} ;$ C. The control rats showed part of the cytoplasm of the Purkinje cell with abundant healthy mitochondria (M) with undamaged membranes and cristae, as well as cisternae of the rough endoplasmic reticulum (rER); D. The group treated with lead acetate showed ballooned and swollen mitochondria (M) with ruptured membranes (arrows) and cristae. Note the vacuolated, empty neuropils (V), and the myelin-like figures in the upper-right corner inset. Scale bar: $500 \mathrm{~nm}$.

Table 2. The number of Purkinje cells per field in the different groups

\begin{tabular}{|c|c|c|c|c|}
\hline Cells type & Control & Lead acetate & $\begin{array}{l}\text { Lead acetate with combined } \\
\text { allicin and vitamin B }\end{array}$ & $\begin{array}{l}\text { Lead acetate with } \\
\alpha \text {-tocopherol }\end{array}$ \\
\hline \multirow[t]{2}{*}{ Purkinje cell N (10) } & $5.50 \pm 3.03$ & $2.90 \pm 1.37$ & $3.00 \pm 1.49$ & $5.50 \pm 2.07$ \\
\hline & & $p=0.009^{1}$ & $p=0.011^{1} ; p=0.916^{2}$ & $p=1.000^{1} ; p=0.009^{2}$ \\
\hline \multirow[t]{2}{*}{ Granular cells N (10) } & $273.00 \pm 22.14$ & $206.00 \pm 22.21$ & $229.50 \pm 16.66$ & $257.50 \pm 10.87$ \\
\hline & & $\mathrm{p}<0.0001^{1}$ & $p=0.011^{1} ; p=0.008^{2}$ & $\mathrm{p}=0.070^{1} ; \mathrm{p}<0.0001^{2}$ \\
\hline
\end{tabular}

Values are expressed as mean \pm standard deviation. The analysis was made using a one-way ANOVA test (least significant difference); ${ }^{1} \mathrm{p}$ : significance vs. control; ${ }^{2} \mathrm{p}$ : significance vs. lead group

Purkinje and granular cells number was insignificantly different from controls but was significantly higher than lead acetate group (Table 2).

\section{DISCUSSION}

Lead poisoning has been a persistent public health problem throughout the world for many years. Pre- 
vious studies have indicated that lead can be highly concentrated in the brain, placenta, and umbilical cord [49]. The cerebellar lesion has been observed in a number of animals as muscle-mass weakness, tremors, lack of stability and balance, gait disturbances, and hind-limb paralysis [39]. Lead acetate seems to be stored in the cerebellum, disturbing its physiology as well as causing neurotoxicity, cellular deterioration, and possibly cellular death [18, 37].

Selective architectural alterations within the Purkinje cells could possibly be related to cerebellar involvement; subsequent motor ataxia, which was found in the current study, was explained by a previous study [50]. The morphological modifications seen in cerebellum throughout the current research are supported by previous neuropathological studies that demonstrated alterations in the cerebral cortex following lead exposure [14].

In the present study, deformed shrinkage Purkinje cells with vacant areas were noticed in lead acetate-treated rats. These findings agree with a previous study that attributed the shrinkage of Purkinje cells to be a consequence of a destructive process related to morphological and functional biosynthesis associated with cellular proteins [49].

The Purkinje cells' deterioration observed in the current work involved affected rough endoplasmic reticulum cisternae and deformed Golgi cisternae. Since these organelles make up the protein synthesising system, their particular involvement may reduce the neuronal capability to provide protein, which could lead to the disability of nerve cell capabilities. Unhealthy, ballooned mitochondria, together with rarified matrices and ill-identified cristae, were observed in the cytoplasm of the Purkinje cells; these findings have already been described in hippocampal neurons in lead-treated rats [52]. It has been suggested that the principal influence of lead acetate on the cerebellum is the suppression of mitochondrial oxidative activity [24].

The myelin-like figures that appeared in the cytoplasm of the Purkinje cells in the current study agree with the findings observed in the neuronal body of the cerebellum in diabetic rats, which has been attributed to degenerated mitochondria [23].

Ultrastructural modifications in the form of dilated Golgi, mitochondrial swelling with disruption of their cristae, and nuclear geometrical irregularity were observed in the lead acetate-treated group in the present work. The same results were discussed by a previous researcher, who considered these disorders due to direct toxicity on neuronal tissues, which induces prohibition of the oxidative phosphorylation, the irregular manufacture of proteins, and malfunction of the detoxification process [43]. Golgi cells appeared in the current work as electron-dense particles in lead-treated rats; this affliction created serious motor ailments in mice [6].

Previous studies have discussed the ameliorative role of combined Allium sativum and vitamin B-complex against lead acetate-induced toxicity and have proved the potency of these combined substances [27]. It has been found that allicin role is not only ameliorative against lead toxicity, but the plant also contains chelating compounds capable of enhancing the elimination of lead [36]. In the present study, groups that were treated with allicin combined with vitamin B-complex showed partial recovery of Purkinje cells, and the ultrastructure alterations were less than those in the lead acetate-treated group. The presence of healthy mitochondria, with a dense matrix and well-defined cristae, suggest the detoxification of Purkinje cells caused by lead toxic effects.

In the current work, the administration of $\alpha$-tocopherol prior to the administration of lead acetate diminished the signs of neurotoxicity. This finding is in agreement with a previous work that showed that $\alpha$-tocopherol enhances the vitality of nerve cells [3]. Furthermore, $\alpha$-tocopherol functions as a cofactor in the manufacture of crucial fatty acids, and plays a part in the synthesis of neurotransmitters that include 5-hydroxytryptamine, dopamine, noradrenaline, and gamma-aminobutyric acid (GABA); GABA contributes to the normal performance of the nervous system $[5,35]$.

In the present research, a tremendous rise in GFAP-positive astrocytes was discovered immediately after lead acetate treatment compared with the control animals. Some researchers have described an elevated GFAP content in various regions of the brain tissue, mainly in the hippocampus and the cerebellar cortex [20]. Consequently, the determination of GFAP expression could possibly be a suitable marker for comprehending neurodegenerative alterations. Gliosis that develops in the lead acetate-treated groups could possibly be caused by the creation of free radicals [20]; antioxidants may minimise such a reactive gliosis, probably through reduction of the hazardous impact of ROS in the CNS [11]. An earlier work has described that allicin alters the GFAP content in various 
brain regions and has a principal neuroprotective influence in minimising neuroglia injury in the CNS [11]. On such a basis, the usage of either $\alpha$-tocopherol or combined allicin and vitamin B-complex in the current research considerably diminished GFAP expression in rats' cerebellar cortices.

The limitations of the study are due to the number of animals that might be larger and the fixed dose that might be variant. Quantitative measures as stereology and immunostains for the morphology of Purkinje cells as calbindin D-28k are recommended to support the hypothesis of the study. Also, clinical studies dealing with motor coordination changes might confirm the findings of the study.

\section{CONCLUSIONS}

The preceding data finds that lead is among the most common environmental poisons affecting the cerebellum. The promising ameliorative potentials of $\alpha$-tocopherol or combined allicin and vitamin B-complex are considered good candidates for the therapeutic intervention against lead poisoning. And are advised as a possible adjuvant therapy in ameliorating the consequences associated with lead poisoning. Also, current findings suggest, that the efficacy of $\alpha$-tocopherol is higher than that of combined allicin and vitamin B-complex.

\section{ACKNOWLEDGEMENTS}

This work was funded by the Deanship of Scientific Research (DSR), King Abdulaziz University, Jeddah, Saudi Arabia under Grant No. 140-262-D1435. The authors, therefore, acknowledge and thank the DSR for technical and financial support.

\section{REFERENCES}

1. Abd El-Monem DD (2012) The modulating effect of melatonin against the genotoxicity of lead acetate. J Basic Appl Zoology, 65: 223-231.

2. Abdel Moneim AE, Dkhil MA, Al-Quraishy S (2011) The protective effect of flaxseed oil on lead acetate-induced renal toxicity in rats. J Hazard Mater, 194: 250-255.

3. Amadio S, D'Ambrosi N, Trincavelli ML, Tuscano D, Sancesario G, Bernardi G, Martini C, Volonté C (2005) Differences in the neurotoxicity profile induced by ATP and ATP $\gamma$ in cultured cerebellar granule neurons. Neurochem Int, 47: 334-342.

4. Aminuddin M, Partadiredja G, Sari DC (2015) The effects of black garlic (Allium sativum $\mathrm{L}$ ) ethanol extract on the estimated total number of Purkinje cells and motor coordination of male adolescent Wistar rats treated with monosodium glutamate. Anat Sci Int, 90: 75-81.

5. Araujo JA, Landsberg GM, Milgram NW, Miolo A (2008) Improvement of short-term memory performance in aged beagles by a nutraceutical supplement containing phosphatidylserine, Ginkgo biloba, vitamin E, and pyridoxine. Can Vet J, 49: 379-385.

6. Balk EM, Raman G, Tatsioni A, Chung M, Lau J, Rosenberg IH (2007) Vitamin B6, B12, and folic acid supplementation and cognitive functiona systematic review of randomized trials. Arch Int Med, 167: 21-30.

7. Bastian AJ (2011) Moving, sensing and learning with cerebellar damage. Curr Opin Neurobiol, 21: 596-601.

8. Baydas G, Nedzvetskii VS, Tuzcu M, Yasar A, Kirichenko SV (2003) Increase of glial fibrillary acidic protein and S-100B in hippocampus and cortex of diabetic rats: effects of vitamin E. Eur J Pharmacol, 462: 67-71.

9. Baydas G, Reiter RJ, Yasar A, Tuzcu M, Akdemir I, Nedzvetskii VS (2003) Melatonin reduces glial reactivity in the hippocampus, cortex, and cerebellum of streptozotocin-induced diabetic rats. Free Radic Biol Med, 35: 797-804.

10. Baydas G, Tuzcu M, Yasar A, Baydas B (2004) Early changes in glial reactivity and lipid peroxidation in diabetic rat retina: effects of melatonin. Acta Diabetol, 41: 123-128.

11. Bellé LP, De Bona KS, Abdalla FH, Pimentel VC, Pigatto AS, Moretto MB (2009) Comparative evaluation of adenosine deaminase activity in cerebral cortex and hippocampus of young and adult rats: effect of garlic extract (Allium sativum $\mathrm{L}$ ) on their susceptibility to heavy metal exposure. Basic Clin Pharmacol Toxicol, 104: 408-413.

12. Burki TK (2012) Nigeria's lead poisoning crisis could leave a long legacy. Lancet, 379: 792.

13. Chow CK (1990) Effect of dietary vitamin $E$ and selenium on rats: Pyruvate kinase, glutathione peroxidase and oxidative damage. Nutr Res, 10: 183-194.

14. Costa LG, Aschner M, Vitalone A, Syversen T, Soldin OP (2004) Developmental neuropathology of environmental agents. Annu Rev Pharmacol Toxicol, 44: 87-110.

15. Cutler RR, Odent M, Hajj-Ahmad H, Maharjan S, Bennett NJ, Josling PD, Ball V, Hatton P, Dall'Antonia M (2009) In vitro activity of an aqueous allicin extract and a novel allicin topical gel formulation against Lancefield group B streptococci. J Antimicrob Chemother, 63: 151-154.

16. Das I, Saha T (2009) Effect of garlic on lipid peroxidation and antioxidation enzymes in DMBA-induced skin carcinoma. Nutrition, 25: 459-471.

17. Feeser VR, Loria RM (2011) Modulation of traumatic brain injury using progesterone and the role of glial cells on its neuroprotective actions. J Neuroimmunol, 237: 4-12.

18. FitzGerald JT, Gruener G, Mtui E (2011) Clinical Neuroanatomy and Neuroscience: Elsevier Health Sciences, UK.

19. Flora G, Gupta D, Tiwari A (2012) Toxicity of lead: a review with recent updates. Interdiscip Toxicol, 5: 47-58.

20. Gonzalez A, Pariente JA, Salido GM (2007) Ethanol stimulates ROS generation by mitochondria through $\mathrm{Ca} 2+$ mobilization and increases GFAP content in rat hippocampal astrocytes. Brain Res, 1178: 28-37.

21. Gu X, Wu H, Fu P (2013) Allicin attenuates inflammation and suppresses HLA-B27 protein expression in ankylosing spondylitis mice. Biomed Res Int, 2013: 171573.

22. Harrison DG, Guzik TJ, Lob HE, Madhur MS, Marvar PJ, Thabet SR, Vinh A, Weyand CM (2011) Inflammation, immunity, and hypertension. Hypertension, 57: 132-140.

23. Hernández-Fonseca JP, Rincón J, Pedreañez A, Viera N, Arcaya JL, Carrizo E, Mosquera J (2009) Structural and ultrastructural analysis of cerebral cortex, cerebellum, and hypothalamus from diabetic rats. Exp Diabetes Res, 2009: 329632. 
24. Hossain MA, Russell JC, Miknyoczki S, Ruggeri B, Lal B, Laterra J (2004) Vascular endothelial growth factor mediates vasogenic edema in acute lead encephalopathy. Ann Neurol, 55: 660-667.

25. Huang F, Schneider J (2004) Effects of lead exposure on proliferation and differentiation of neural stem cells derived from different regions of embryonic rat brain. Neurotoxicology, 25: 1001-1012.

26. Hussein AM, Badawoud MH, Mustafa, HN (2013) The effects of diethylstilbestrol administration on rat kidney Ultrastructural study. Saudi Med J, 34: 1114-1124.

27. Khan M, Mostofa M, Jahan M, Sayed M, Hossain M (2009) Effect of garlic and vitamin B-complex in lead acetate induced toxicities in mice. Bangl J Vet Med, 6: 203-210.

28. Kilikdar D, Mukherjee D, Mitra E, Ghosh AK, Basu A, Chandra AM, Bandyoapdhyay D (2011) Protective effect of aqueous garlic extract against lead-induced hepatic injury in rats. Indian J Exp Biol, 49: 498-510.

29. Li Y, Xu Sy (2007) Preparation of Garlic Powder with High Allicin Content by using combined microwave-vacuum and vacuum drying as well as microencapsulation. J Food Eng, 83: 76-83.

30. Malecka A, Jarmuszkiewicz W, Tomaszewska B (2001) Antioxidative defense to lead stress in subcellular compartments of pea root cells. Acta Biochim Pol, 48: 687-698.

31. Mousa AM, Al-Fadhli AS, Rao MS, Kilarkaje N (2015) Gestational lead exposure induces developmental abnormalities and up-regulates apoptosis of fetal cerebellar cells in rats. Drug Chem Toxicol, 38: 73-83.

32. Mustafa HN (2012) Effect of acrylamide on testis of albino rats Ultrastructure and DNA cytometry study. Saudi Med J, 33: 722-731.

33. Mustafa HN, El Awdan SA, Hegazy GA (2013) Protective role of antioxidants on thioacetamide-induced acute hepatic encephalopathy: biochemical and ultrastructural study. Tissue Cell, 45: 350-362.

34. Nagata M (2005) Inflammatory cells and oxygen radicals. Curr Drug Targets Inflamm Allergy, 4: 503-504.

35. Palan PR, Shaban DW, Martino T, Mikhail MS (2004) Lipid-soluble antioxidants and pregnancy: maternal serum levels of coenzyme Q10, alpha-tocopherol and gamma-tocopherol in preeclampsia and normal pregnancy. Gynecol Obstet Invest, 58: 8-13.

36. Pourjafar M, Aghbolaghi P, Shakhse-Niaie M (2007) Effect of garlic along with lead acetate administration on lead burden of some tissues in mice. Pak J Biol Sci, 10: 2772-2774.

37. Ronchetti R, Hazel P, Schoeters G, Hanke W, Rennezova Z, Barreto M, Villa MP (2006) Lead neurotoxicity in children: Is prenatal exposure more important than postnatal exposure? Acta Paediatr Suppl, 95: 45-49.

38. Roshan VD, Assali M, Moghaddam AH, Hosseinzadeh M, Myers J (2011) Exercise training and antioxidants: effects on rat heart tissue exposed to lead acetate. Int J Toxicol, 30: 190-196.

39. Schmahmann JD (2004) Disorders of the cerebellum: ataxia, dysmetria of thought, and the cerebellar cognitive affective syndrome. J Neuropsychiatry Clin Neurosci, 16: 367-378.
40. Sepúlveda A, Schluep M, Renaud FG, Streicher M, Kuehr R, Hagelüken C, Gerecke AC (2010) A review of the environmental fate and effects of hazardous substances released from electrical and electronic equipments during recycling: examples from China and India. Environ Impact Asses Rev, 30: 28-41.

41. Sharma V, Sharma A, Kansal L (2010) The effect of oral administration of Allium sativum extracts on lead nitrate induced toxicity in male mice. Food Chem Toxicol, 48: 928-936.

42. Shrivastava $S$ (2012) Amelioration of aluminium induced toxicity by Allium sativum. Sci Res Essays, 8: 168-177.

43. Sobaniec-Lotowska ME (2003) Ultrastructure of astrocytes in the cortex of the hippocampal gyrus and in the neocortex of the temporal lobe in experimental valproate encephalopathy and after valproate withdrawal. Int J Exp Pathol, 84: 115-125.

44. Sofroniew MV (2014) Multiple roles for astrocytes as effectors of cytokines and inflammatory mediators. Neuroscientist, 20: 160-172.

45. Suvarna KS, Suvarna SK, Layton C, Bancroft JD (2012) Bancroft's Theory and Practice of Histological Techniques, Expert Consult: Online and Print, 7: Bancroft's Theory and Practice of Histological Techniques: Elsevier Health Sciences.

46. Thach W (2014) Does the cerebellum initiate movement? Cerebellum, 13: 139-150.

47. Verhagen $H$, Buijsse $B$, Jansen $E$, Bueno-de-Mesquita B (2006) The state of antioxidant affairs. Nutr Today, 41 : 244-250.

48. Victery W (1988) Evidence for effects of chronic lead exposure on blood pressure in experimental animals: an overview. Environ Health Perspect, 78: 71-76.

49. Villeda-Hernandez J, Mendez Armenta M, Barroso-Moguel R, Trejo-Solis M, Guevara J, Rios C (2006) Morphometric analysis of brain lesions in rat fetuses prenatally exposed to low-level lead acetate: correlation with lipid peroxidation. Histol Histopathol, 21: 609-617.

50. Wang Y, Wang S (2011) Effects of lead exposure on histological structure and antioxidant capacity in the cerebellum of 30-day-old mice. Neural Regen Res, 6: 1077-1081.

51. Wilhelmsson U, Li L, Pekna M, Berthold CH, Blom S, Eliasson C, Renner O, Bushong E, Ellisman M, Morgan TE, Pekny M (2004) Absence of glial fibrillary acidic protein and vimentin prevents hypertrophy of astrocytic processes and improves post-traumatic regeneration. J Neurosci, 24: 5016-5021.

52. Xu J, Yan H, Yang B, Tong L, Zou Y, Tian Y (2009) Effects of lead exposure on hippocampal metabotropic glutamate receptor subtype 3 and 7 in developmental rats. J Negat Results BioMed, 8: 5.

53. Yousef MI, Awad TI, Mohamed EH (2006) Deltamethrin-induced oxidative damage and biochemical alterations in rat and its attenuation by vitamin E. Toxicology, 227: 240-247.

54. Zhi-Wei Z, Ru-Lai Y, Gui-juan D, Zheng-yan Z (2005) Study on the neurotoxic effects of low-level lead exposure in rats. J Zhejiang Univ Sci B, 6: 686-692. 